\title{
Occupational Medicine in cardiovascular risk prevention by ergometry and psycho test implementing physical activities in Public Health Institute employees
}

\author{
Lalic Hrvoje* \\ Occupational and Sports Medicine, Health Centre Rijeka, Medical School University, Rijeka, Croatia
}

Received: July 23, 2015

DOI: $10.5430 /$ jha.v4n6p89
Accepted: August 30, 2015

Online Published: September 24, 2015

URL: http://dx.doi.org/10.5430/jha.v4n6p89

\begin{abstract}
Within the WHO global action against chronic noninfectious diseases the local action in cooperation of Occupational Medicine and Sports and Public Health Institute in Rijeka, Croatia has been undertaken. The Project objectives were improvement of psychophysical condition of women employed in the Institute and also to spark their interest in health and physical activities. The research comprised ergometry testing 19 female employees and so the levels of glucose and lactate were tested before and after ergometry burden. They have undergone the battery of psycho tests, stress test, test of anxiety as condition, test of anxiety as trait personality and test of depression. They had 6 weeks of physical exercises 1 hour twice a week monitored by a kinesiologist. After the exercises the results proved positive but not statistically due to short period of exercises. The Scout lactate test $p=.357, p>.05$ indicated a minor increase of lactate after the bicycle ergometry burden test and conducted programmed exercises in relation to the bicycle ergometry burden test before the exercises. Bionime glucose test after the burden and exercise showed a decrease but smaller compared to the burden test before exercises, $p=.250, p>.05$ which indicates improved fitness though not significant. Concerning psychic parameters the exercises resulted in significant differences in depression, $p=.0197, p<.05$. In conclusion, besides the importance of carrying out such programmed physical activities, diagnosed Electrocardiograph (ECG) changes, of 19 employees one was cosmetic and one cardiac organic change, point to the significance of screening in Occupational Medicine and Sports in diagnosing potential cardiac diseases in working population.
\end{abstract}

Key Words: Ergometry, Programmed physical activities, Psycho tests, Occupational and Sports Medicine

\section{INTRODUCTION}

As long ago as $2006 \mathrm{WHO}$ and its regional office for Europe convened Ministry Conference to begin the struggle against obesity. Then the organized fight against chronic diseases started. Chronic diseases, hypertony, diabetes, carcinomas, psychical disturbances are connected with the sedentary way of life. Lifestyle could be changed already in the very first schooldays. Preventing physical inactivity and weight gain during college is critical in decreasing lifelong obesity and associated disease risk. ${ }^{[1]}$ Nowadays we often meet the diagnosis of metabolic syndrome that includes systolic blood pressure $>130$, diastolic pressure $>85$, fasting serum glucose $>110 \mathrm{mg} / \mathrm{dl}$, high density lipoprotein plasma cholesterol $<40 \mathrm{mg} / \mathrm{dl}$, plasma triglycerides $>150 \mathrm{mg} / \mathrm{dl}$, waist circumference $>102 \mathrm{~cm}$ (men) or $88 \mathrm{~cm}$ (women). ${ }^{[2]}$ Chronic stress through deregulation of the hypothalamic-pituitary

\footnotetext{
*Correspondence: Lalic Hrvoje; Email: halalic@inet.hr; Address: Occupational and Sports Medicine, Health Centre Rijeka, Medical School University, Rijeka, Croatia.
} 
adrenal (HPA) axis is also involved in the development of the syndrome. ${ }^{[3]}$ An increasing number of studies enhance significance of physical activities and the diet. Also marital relations influence cardiovascular health. ${ }^{[4]}$ Physical activities can influence preventing cognitive impairment and dementia. ${ }^{[5]}$ For example, soccer practice appears able to improve psychophysical health in individuals with diagnosis of schizophrenia. ${ }^{[6]}$ Furthermore, despite evidence that exercise has been found to be effective in the treatment of depression it is unclear whether these data can be extrapolated to bipolar disorder. ${ }^{[7]}$

The employer role is very important in promoting healthy lifestyle. But unfortunately in practice a range of perspectives were identified, from active support through uncertainty and cynicism to resistance. ${ }^{[8]}$ It is important to educate managers on the benefits of healthy lifestyle. Healthy worker can achieve better and more results at the workplace. Employees on the way to workplace or home often get injured due to banal reasons, loss of balance, falls etc. For that reason it is important to introduce various types of exercise interventions, active joint repositioning, force sense, co-ordination, muscle performance, balance training, plyometric and vibration training. ${ }^{[9]}$

Generally, a combined aerobic and resistance exercise programme can improve cardiovascular risk factors in hypertensive subjects. The same programme induces improvement in exercise tolerance and flexibility variables in cancer survivors. ${ }^{[10]}$

The task and obligation of every physician is to assess each patient's exercise habits and inform him of the risks of being sedentary. ${ }^{[11]}$ Many studies have shown a linear relationship between one's activity level and heart health, leading to the conclusion that "if some exercise is good, more must be better". However one should be careful because very high doses of excessive exercise may lead to cardiac dilatation, cardiac dysfunction and may be associated with increased risk of atrial fibrillation and malignant ventricular arrhythmias. ${ }^{[12]}$

The intention of this research was to enter the program of local action within global directed to HEPA (health enhancing physical activity).

We implemented program of physical exercises with the participation of 19 female employees. The aim was to show objectively how important the implementation of programmed exercises can be for employees with sedentary occupations. In relation to the cited literature, which mostly shows significant improvements of psychophysical status, current research address the benefits of implementing the proposed program.

\section{Materials AND METHOdS}

\subsection{Participants}

The research was approved by the Ethics Committee (08-820-61/16-15) of the Educational Public Health Institute of Littoral - Mountainous County. In line with the Helsinki declaration each of the participants signed approval for participation in the research.

Medical examination was conducted by 19 examinees employed in Educational Public Health Institute of Littoral - Mountainous County. The mean age was 47.53 years (33-62 range $\pm 8.329 S D$ ). Their mean employment history was 24.63 years (7-38 range $\pm 7.38 S D$ ). Body mass index mean was 26 (19-37 range $\pm 5.002 S D)$. Systolic blood pressure mean was $114(90-145$ range $\pm 16.70 S D)$ and diastolic pressure was mean 75 (60-90 range $\pm 8.64 S D)$.

\subsection{Methods}

The examinees were burdened on the bicycle ergometer Btl Ergo Win 08. Examination on bicycle ergometer was done before and after the exercises. Before and after cycling glucose and lactate levels were measured as well as after the exercises. The participants have also undergone a test for psychical stress, anxiety and depression, i.e. the PSS-10 Cohen stress test, Stai $\chi_{1}$ and Stai $\chi_{2}$ tests (anxiety as condition and personality trait) as well as the Beck's scale of depression.

A kinesiology expert led programmed exercises in duration of one hour two times per week through six weeks. Exercises were used to improve balance, aerobic capacity, agility, plyometric exercises, general relaxation exercises with music, exercises to strengthen cervical and lumbal parts of vertebra, exercises to strengthen hip joints. The exercises took place in a gym hall near their workplace.

\subsection{Statistical analysis}

The computer programme Stat Soft Statistic Version 10 was used for statistical analyses. The individual differences recorded among employees before and after the exercises were analyzed by the Kruskal-Wallis Test. A $p$-value less than .05 is considered statistically significant different.

\section{RESUltS}

In two (10\%) out of 19 examinees Electrocardiograph (ECG) changes were detected. By further stress ergometry monitoring it was proved that in one examinee incomplete branch block represents not only cosmetic change but organic cardiac disease. That patient is now on cardiology examination and anticoagulant therapy. In the other examinee more than one ECG change represents only "cosmetic defect", because incomplete right branch block + posterior left hemi block does not develop clinical manifestations on ergometry. 
Table 1 show data about the examinees' mean age, years of employment, body mass index, systolic and diastolic blood pressure as well as heart rate at burden.

Table 1. Examinees' basic antropometric and cardiovascular values

\begin{tabular}{ll}
\hline Characteristics & Value (mean) \\
\hline No of patients & 19 \\
Age & 47.53 \\
Years of employment & 24.53 \\
Body mass index & 26 \\
Blood pressure systolic & 114 \\
Blood pressure dyastolic & 75 \\
ECG (pathologic) & 2 \\
Blood pressure systolic at burden & 160 \\
Blood pressure diastolic at burden & 80 \\
Heart rate at burden & 145 \\
\hline
\end{tabular}

Table 2 show data about the examinees' glucose level test at rest, glucose level test at burden, lactate level test at rest, lactate level test at burden as well as Beck's depression scale before and after the burden.

Table 2. Examinees' glucose and lactate levels at rest/burden and Beck's depression scale results

\begin{tabular}{ll}
\hline Characteristics & Value (mean) \\
\hline No of patients & 19 \\
Glucose level test at rest in mmol/L & 5.62 \\
Glucose level test at burden in mmol/L & 4.92 \\
Lactate level test at rest in mmol/L & 1.91 \\
Lactate level test in mmol/L at burden & 4.32 \\
Beck's depression scale before the exercises-points & 3.57 \\
Beck's depression scale after the exercises-points & 2.21 \\
\hline
\end{tabular}

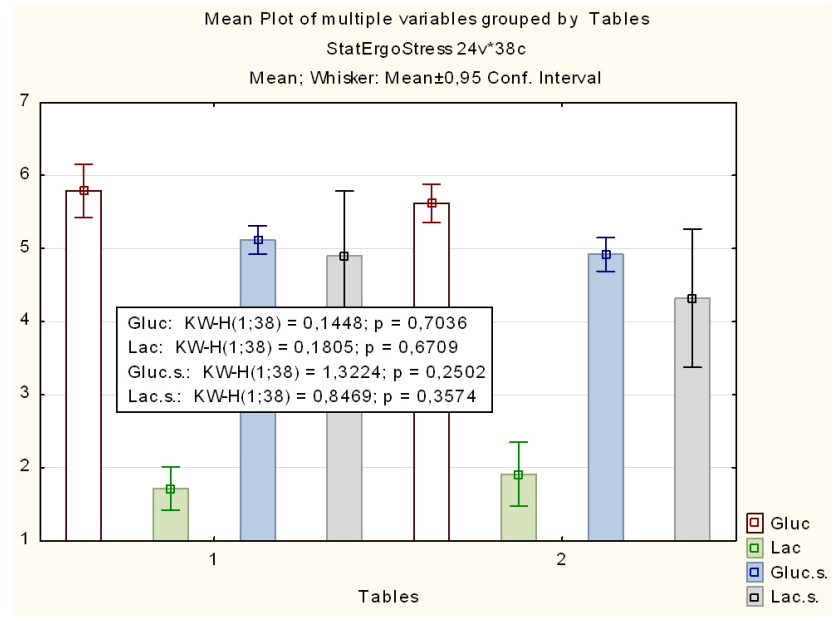

Figure 1. Lactate levels after the exercises

Lactate levels after the exercises decreased, although statistically non-significantly

Published by Sciedu Press

\section{Results after exercises}

The exercises have not changed statically significantly the measured blood parameters, although they resulted in positive improvements in direction of a slight decrease of glucose at stress burden, $p=.250, p>.05$, as well as of a slight lactate increase under the stress, $p=.357, p>.05$ (see Figure 1).

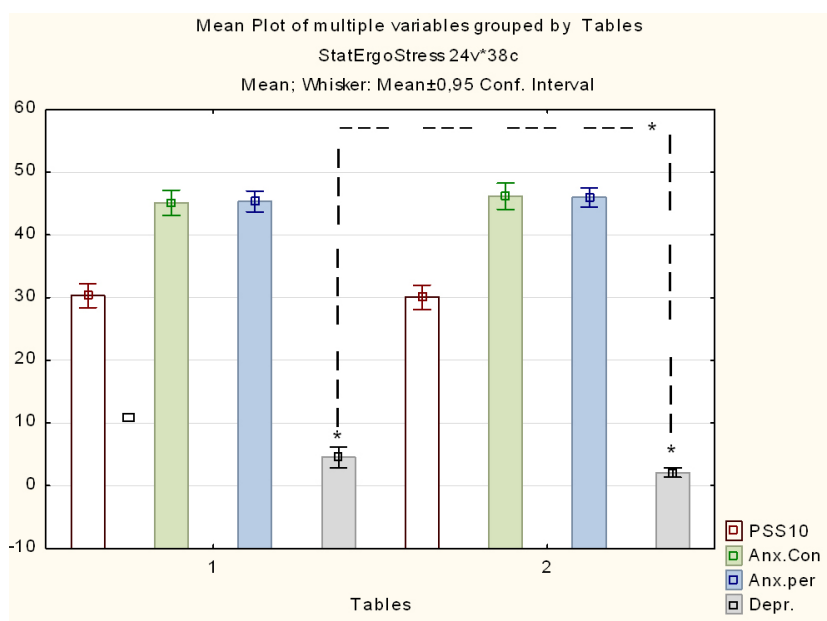

Figure 2. Psychical condition before and after exercises Depression is statistically significantly lower after the exercises, $p=.0197, p<.05$

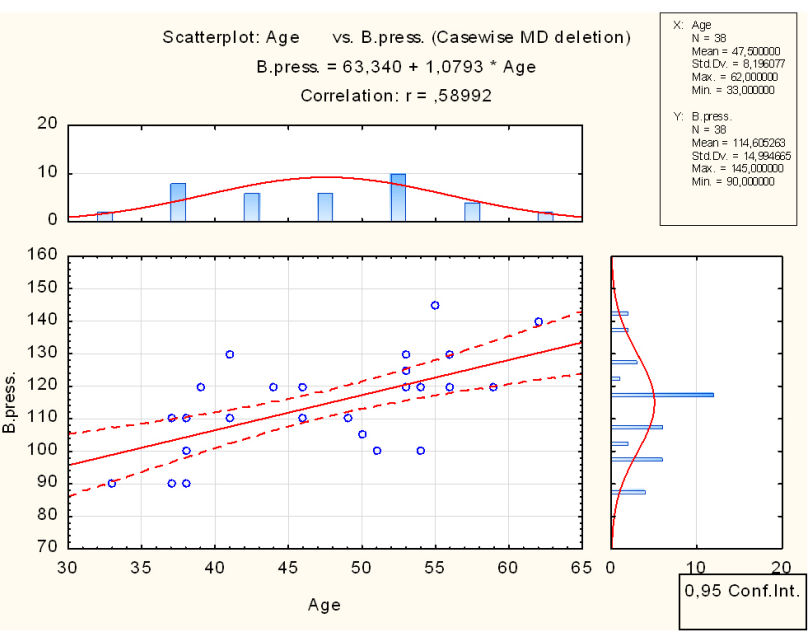

Figure 3. Linear regression analysis between age and blood pressure

Linear regression analysis shows strong positive correlation between age and blood pressure

After the exercises there was statistically significant difference regarding depression, $p=.0197, p<.05$ (see Figure 2).

Linear regression analysis showed strong positive correlation between age and blood pressure, $r=+0.58$ (see Figure 3 ). 


\section{Discussion}

The first aim of the research was to improve the psychophysical status of the Public Health Institute employees. The other aim was to arouse the employees' interest in health habits and exercises. But the received results revealed a new significance of the conducted research. These are ergometry results that help us make patients' screening of cardiovascular diseases and ECG changes. Namely, ECG changes found in 2 employees out of 19 at our Occupational and Sports Medicine Department show the importance of such examinations. We have concluded that in one patient there are only cosmetic ECG changes, but in the other patient we have found organic cardiac disease. That patient is now under the control and therapy at the Cardiology Department. It means that we can expect incidence of more than $10 \%$ of cardiac diseases and ECG changes in employees that have mostly sedentary job. Sometimes, like in the described case, small ECG changes like incomplete right branch block reveal atrial septum defect and other defects. In the other case, combined changes, incomplete right branch block + rear left hemi block, remained only cosmetic, i.e. the patient under the burden had no clinical disturbances or signs of cardiac ischemia. Those screenings performed in employees are of great importance. Diagnosed patients could be treated and potential complications avoided.

Generally, exercise can improve self-esteem and positive outlook in life. ${ }^{[13]}$ Physical activities have been shown to reduce symptoms of anxiety although a relatively small sample size of examinees is limited factors for assessment. ${ }^{[14]}$

Exercises have shown positive influence on depression in our research. Namely, the used Beck's depression scale after conducted exercises showed in examinees total depression absence which was statistically significant in compared to the situation before exercises, when low depression prevailed. Even before the exercises examinees were not depressed (low level of depression) but now we can say that they are in good mood, with a new life enthusiasm as well as with a new working enthusiasm.

Moderate stress has been presented before and after exercises which can be expected for women population working two shifts - at work in the morning and at home in the afternoon. Both tests of anxiety, Stai $\chi_{1}$, anxiety as the condition, and Stai $\chi_{2}$, anxiety as the trait personality, before and after exercises showed high level of anxiety, but the bottom line of high leveled anxiety. It means that it is important to carry out the mentioned exercises with an emphasis on relaxation elements including relaxing music.

There were more studies conducted for occupational athletes as firefighters, soldiers and police officers than for sedentary occupations. ${ }^{[15]}$ Workers in such active occupations wear protective clothing and footwear so they are always interesting for researchers. ${ }^{[16]}$

Great efforts have been made to start such research at Public Health Institute with their sedentary employees. It was necessary to convince the Institute managers to accept our Occupational and Sports Medicine proposal. Since the Educational Institute is the leader in various preventive programs in our county cooperation was soon established. Although our proposal for exercises and ergometry caused great interest among employees, in the end only 19 joined to the program. The examination included lactate and glucose measurement before and after ergometry repeatedly after six weeks. Although a drop of capillary blood was taken, written acceptance according to the Helsinki declaration was required

A lot of research on anaerobic and aerobic capacities measuring glucose and lactate has been done on animal models. ${ }^{[17]}$ Different intensity exercise intervention can reduce blood glucose and improve insulin sensitivity. ${ }^{[18]}$ Exercise is associated with decreased plasma glucose. ${ }^{[19]}$ In our research lactate decreased after the stress ergometry to the state before the exercises and glucose falls decrease. Glucose always falls after the stress ergometry but after the exercises it decreased less and lactate increased also less which means employees' fitness increased, that aerobic capacity improved, oxygen uptake was better used and organism demanded less anaerobic energy sources. That all shows that we have accomplished the aim set before, the achieved progress is important, but not statistically significant. The exercise period was too short to achieve significant difference in such type of examinees mean aged 47 years. Especially intermittent exercise increases skeletal muscle oxidative capacity. ${ }^{[20]}$ Aerobic exercise training promotes the effectiveness of medical treatment in type 2 diabetes mellitus. ${ }^{[21]}$ Such interventions are very usable where obesity occurs besides diabetes. ${ }^{[22]} \mathrm{In}$ termittent training shows better results than continuous one for lactate decreasing. ${ }^{[23]}$ Such training influences maximal lactate steady state and delay time to exhaustion. ${ }^{[24]}$ Time to exhaustion at maximal lactate steady state is similar for cycling and running. ${ }^{[25]}$

Power of examinee at ergometry burdening depends on respiratory exchange ratio and predicts maximal lactate steady state. ${ }^{[26]}$ Before ergometry the patient should be carefully examined. Acute respiratory diseases, increased body temperature, diabetes accompanied with complications, recent cardiac infarction, and malignant diseases are some of important contraindications for ergometry.

Environmental factors should not be neglected, too cold or 
too hot examining room is forbidden.

Hypotonic sports drinks may help to offset fluid losses and attenuate some inflammatory responses to exercise. ${ }^{[27]}$

In sedentary middle-aged adults the best results are shown by low-volume interval training that improves muscle oxidative capacity. ${ }^{[28]}$

Considering that in the examined group included women aged 62 , the coach had a difficult task to find mean burdened exercises for all participants. Older women have higher values of blood pressure. The vessels become more rigid, so exercise and healthy nourishment can prevent atherosclerotic changes. Atherosclerotic vessels become narrow and automatically blood pressure increases.

As evident from the results the exercises have improved the examinees psycho physical status. All the references used in this paper referring to the observed problem can confirm this statement. However, in this paper we also emphasize that this cannot be achieved easily. Furthermore, although improvements in examinees' physical condition have been achieved, the improvements have not been significant. Significant improvements have only been achieved in terms of meliorating psychical status and alleviating depression. This means that further exercises must be conducted, that the employees must continue exercising at home and that in order to achieve better fitness levels they must change their lifestyle. The purpose of this paper is to fill in a certain gap in existing relevant literature. Namely, although it has been proven that physical exercises can improve one's psycho physical status, we have in this paper shown that realistically, this occurs gradually. After a six-week period of programmed exercises it is possible to register improvements, although, statistically, this may not be relevant because of the unique sample of the population observed and because of the relative shortness of the period of observation. Nevertheless, we may conclude that the employees have to continue making conscious efforts and demonstrate determination in order to improve their status. Help provided by medical doctors and kinesiology experts alone is usually not enough.

\section{Conclusion}

Our Occupational and Sports Medicine accomplished its goals improving psychophysical status of Institute employees that participated in programmed exercises. We have challenged employees to continue exercising and attracted others to join our program. We hope for positive response in the whole county and elsewhere. What is most important we pointed to the importance of such cardiovascular screening in working population for revealing and preventing cardiovascular diseases.

\section{REFERENCES}

[1] Many GM, Lutsch A, Connors K, et al. Examination of lifestile behaviors and cardiometabolic risk factoed in University students enrolled in kinesiology degree programs. J Strenght Cond Res. 2015 [Epub ahead of print]. PMid: 25647655.

[2] Mancia G, Bombelli M, Facchetti R, et al. Impact of different definitions of the metabolic syndrome on the prevalence of organ damage, cardiometabplic risk and cardiovascular events. J Hypertens. 2010; 28(5): 999-1006.

[3] Amihaesei IC, Chelaru L. Metabolic syndrome a widespread treatening condition; risk factors, diagnostic criteria, therapeutic options, prevention and controversies: an overwiew. Rev Med Chir Soc Med Nat lasi. 2014; 118(4): 896-900. PMid: 25581945.

[4] O’Flynn AM, McHugh SM, Madden JM, et al. Applying the ideal cardiovascular health metrics to couples: a cross-sectional study in primary care. Clin Cardiolo. 2015; 38(1): 32-8. PMid: 25559214. http://dx.doi.org/10.1002/clc. 22350

[5] Friedman DB, Becofsky K, Anderson LA, et al. Public perceptions about risk and protective factors for cognitive health and impairment: a review of the literature. Int Psychogeriatr. 2015; 16: 1-13. PMid: 25592720. http://dx.doi.org/10.1017/s1041610214 002877

[6] Battaglia G, Alesi M, Inguglia M, et al. Neuropsychiatr Dis Treat. 2013; 9: 595-603. PMid: 23662058. http://dx.doi.org/10.21 $47 /$ NDT . S44066

[7] Thomson D, Turner A, Lauder S, et al. A brrief review of exercise, bipolar disorder, and mechanistic pathways. Front Psychol. 2015; 4(6): 147. PMid: 25788889. http://doi.org./10.3389/fpsyg .2015 .00147

[8] Audrey S, Procter S. Employers' views of promoting walking to work: a qulative study. Int J Behav Nutr Phys Act. 2015; 12(1): 174. PMid: 25778960. http://doi.org/10.1186/s12966

[9] Clark NC, Roijezon U, Treleaven J. Proprioception in musculoskeletal rehabilitation. Part 2: Clinical assessment and intervention. Man Ther. 2015; 20(3): 378-87. PMid: 25787919. http://dx.doi.org /10.1016/j.math.2015.01.009

[10] Stefani L, Maffulli N, Mascherini G, et al. Exercise as prescription therapy: benefits in cancer and hypertensive patients. Transl Med UniSA. 2014; 11: 39-43. PMid: 25674548.

[11] Sallis R. Exercise is medicine: a call to action for physicians to assess and prescribe exercise.PhysSportsmed. 2015; 43(1): 22-6. PMid: 25684558.

[12] Mwabu G. Financing health services in Africa: An assessment of alternative approaches. Working Paper Series 0457. 1990. Washington, DC: World Bank. PMid: 25757005. http://dx.doi.org/10.12 49/JSR. 0000000000000134

[13] Sun YL, Wang J, Yao JX, et al. Physical exercise and mental health: cognition, anxiety, depression and self - concept. Sheng Li Xue Jin Zhan. 2014; 45(5): 337-42. PMid: 25764792. 
[14] Stonerock GL, Hoffman BM, Smith PJ, et al. Exercise as treatment for anxiety: systematic review and analysis. Ann Behav Med. 2015; 49(4): 542-56. PMid: 25697132. http://dx.doi.org/10.1007 /s12160-014-9685-9

[15] Frost DM, Beach TA, Callaghan JP, et al. Exercise-based performance enhancement and injury prevention for firefighters: Contrasting the fitness - and movement - related adaptations to two training methodologies. J Strenght Cond Res. 2015; 29(9): 2441-59. PMid: 25763518. http://dx.doi.org/10.1519/JSC. 0000000 000000923

[16] Lee JY, Kim S, Jang YJ, et al. Component contribution of personal protective equipment to the alleviation of physiological strain in firefighers during work and recovery. Ergonomics. 2014; 57(7): 1068-77. http://dx.doi.org/10.1080/00140139.2014.907449

[17] Beck WF, De Araujo GG, Menezes Scariot PP, et al. Time to exaustion at anaerobic threshold in swimming rats: metabolic investigation Bratisl Lek Listy. 2014; 115(10): 617-21. PMid: 25573727.

[18] Cui J, Bai Y, Li M, et al. Effects of different intensity exercise on blood glucose, adolescent obesity rats insulin sensitivity and RBP4. Wei Sheng Jiu. 2014; 43(4): 535-40. PMid: 25199277.

[19] Yamamoto-Kabasawa K, Hosojima M, Yata Y, et al. Benefits of a 12-week lifestyle notification program including diet and combined aerobic and resistance exercise on albuminuria in diabetic and nondiabetic populations. Clin Exp Nephrol. 2015 [Epup ahead of print]. PMid: 25749830.

[20] Gillen JB, Percival ME, Skelly LE, et al. Three minutes of all-out intermittent exercise per week increases skeletal muscle oxidative capacity and improves cardiometabolic health. PloS One. 2014; 9(11): e111489. PMid: 25365337.

[21] Motahari-Tabari N, Ahmad Shirvani M, Shirzad-E-Ahoodasthy M, et al. The effect of 8 weeks aerobic excercise on insulin resistance in type 2 diabetes: a randomized clinical trial. Glob J Health Sci. 2014; 7(1): 115-21. PMid: 25560330. http://dx.doi.org/10.5539/g jhs.v7n1p115

[22] Healy GN, Winkler EA, Brakenridge CL, et al. Accelerometerderived sedentary and and physical activity time in overweight/obese adults with type 2 diabetes: cross-sectional associationas with cardiometabolic biomarkers. PloS One. 2015; 10(3): e0119140. PMid: 25775249.

[23] Grossl T, de Lucas RD, de Souza KM, et al. Time to exhaustion at intermittent maximal lactate steady state is longer than continous cycling exercise. Appl Physiol Nutr Metab. 2012; 37(6): 1047-53. PMid: 22891876. http://dx.doi.org/10.1139/h2012-088

[24] Dittrich N, de Lucas RD, Beneke R, et al. Time to exhaustion at continuous and intermittent maximal lactate steady state during running exercise. Int J Sports Physiol Perform. 2014; 9(5): 772-6.

[25] Fontana P, Boutellier U, Knopfli-Lenzin C. Time to exhaustion at maximal lactate steady is similar for cycling and running in moderately trained subjects. Eur J Appl Physiolog. 2009; 107(2): 187-92. PMid: 19551404. http://dx.doi.org/10.1007/s00421-009 -1111-9

[26] Leiti T, Mendelson M, Laplaud D, et al. Prediction of maximal lactate steady state in runners with an incremental test on the field. J Sports Sci. 2012; 30(6): 609-16. PMid: 22364376. http: //dx.doi.org/10.1080/02640414.2012.660187

[27] Suzuki K, Hashimoto H, Oh T, et al. The effects of sports drink osmolality on fluid intke and immunoendocrine responses to cycling in hot conditions. J Nutr Sci Vitaminol. 2013; 59(3): 206-12. PMid: 23883691. http://dx.doi.org/10.3177/jnsv.59.206

[28] Hood MS, Little JP, Tarnopolsky MA, et al. Low-volume interval training improves muscle oxidativecapacity in sedentary adults. Med Sci Sports Exerc. 2011; 43(10): 1849-56. PMid: 21448086. 